\title{
Application of Three Scale AHP Method in Nuclear Accident Emergency Decision Making of Equipment System
} Xin $\operatorname{Ren}^{1,2, a}$

\author{
${ }^{1}$ Graduate school, National Defense University, Beijing,100091,China \\ ${ }^{2}$ Medical Protection Laboratory, Naval Medical Research Institute ,Shanghai ,200433, \\ China
}

a13161536501@163.com

Keywords: nuclear emergency; multi-objective decision; AHP method; three scale

\begin{abstract}
When the nuclear accident of equipment system happens, the right decision can be taken to reduce the consequences and harm of the accident. Considering the fuzziness and multi-objective of the nuclear emergency decision of equipment system accident and aiming at the deficiency of the traditional AHP method, the multi-level emergency decision evaluation model has been established by using the three-scale AHP method. This model greatly reduces the subjectivity of evaluation and it has the characteristics of strong operability and good stability. Compared with the calculation results of the fuzzy hierarchy model, this model has the consistent ordering with the advantages and disadvantages of the scheme. However, the model has higher resolution on the optimal scheme, and it has practical guiding significance on nuclear emergency decision.
\end{abstract}

\section{Introduction}

The function of nuclear accident emergency decision system is that the emergency plan can be timely and effectively made according to the accident scenarios when a serious nuclear accident occurs. In this paper, a three scale AHP method is proposed, and the decision evaluation model is established. The model is simple, and the analysis example shows that the model is suitable for the nuclear accident emergency decision of equipment system.

\section{Three scale AHP method}

The specific calculation process is stated as follows:

1) Establish the hierarchical structure model

2) Establish a comparison matrix

$$
a_{i j}= \begin{cases}2 & \text { The ith factor is more important than the } j \text { th } \\ 1 & \text { The ith factor is the same important with the jth factor } \\ 0 & \text { The jth factor is more important than the ith factor }\end{cases}
$$

3) Calculate the importance ranking index $r_{i}$

$$
r_{i}=\sum_{j=1}^{n} a_{i j}
$$

Among them, $r_{i}$ the sum of the elements in the matrix A, and $r_{\max }=\max \left\{r_{i}\right\}, r_{\min }=\min \left\{r_{i}\right\}$

4) Construct the judgment matrix $B$

$$
b_{i j}= \begin{cases}\frac{r_{i}-r_{j}}{r_{\max }-r_{\min }}(b-1)+1 & r_{i}>r_{j} \\ 1 & r_{i}=r_{j} \\ {\left[\frac{r_{j}-r_{i}}{r_{\max }-r_{\min }}(b-1)+1\right]^{-1}} & r_{i}<r_{j}\end{cases}
$$


Among them, $\mathrm{b}$ is the basis comparison scale. Select the most important element A and the least important element $\mathrm{B}$, and the value of $\mathrm{b}$ is obtained according to the importance of the two elements. Define the threshold value variable $\theta$, and $\theta=\frac{A}{B}$, then the value of $\mathrm{b}$ is obtained according to the type (4).

$$
b=\left\{\begin{array}{rr}
1 & 1.0<\theta \leq 1.2 \\
3 & 1.2<\theta \leq 1.5 \\
5 & 1.2<\theta \leq 4.0 \\
7 & 4.0<\theta \leq 6.0 \\
9 & \theta>6.0
\end{array}\right.
$$

5)The optimal transfer matrix $C$ of the judgment matrix $B$

$$
c_{i j}=\frac{1}{n} \sum_{k=1}^{n}\left(\lg \frac{b_{i k}}{b_{j k}}\right)
$$

6) The quasi optimal consistent matrix $D$ of the judgment matrix $B$

$$
d_{i j}=10^{c_{i j}}
$$

7) Calculate the weight $w_{i}$

The calculation method of the weight is as follows: the geometric average method, the logarithm least square method, the characteristic root method and so on. In order to simplify the calculation, this paper uses the geometric average method that is also called the root method.

$$
w_{i}=\frac{\left(\prod_{j=1}^{n} d_{i j}\right)^{1 / n}}{\sum_{k=1}^{n}\left(\prod_{j=1}^{n} d_{i j}\right)^{1 / n}}
$$

8) Calculate the comprehensive weight $W_{i}$

$$
W_{i}=\sum_{k=1}^{n} w_{k} w_{i k}
$$

In type (8), $W_{i}$ is the comprehensive weight of the ith program, $w_{k}$ is the weight of the kth criterion, and $w_{i k}$ is the weight of the ith program and the kth criterion.

\section{Case analysis}

\subsection{Describe the example}

In the middle and late emergency of nuclear power plants, the specific measures should be selected according to the accident circumstances.

Through the calculation of the dose in the accident, the practical emergency plan is as follows: decontamination, evacuation, evacuation and decontamination, and permanent resettlement. The evaluation parameters of the 4 schemes are listed in table 1 .

Tab.1 Parameters of emergency project

\begin{tabular}{cccccc}
\hline & $\begin{array}{c}\text { Health risk of } \\
\text { measures (million) }\end{array}$ & $\begin{array}{c}\text { Collective } \\
\text { dose to } \\
\text { prevent(mSv) }\end{array}$ & $\begin{array}{c}\text { Maximum } \\
\text { dose to } \\
\text { prevent(mSv) }\end{array}$ & $\begin{array}{c}\text { Direct cost } \\
\text { of measure } \\
\text { (million) }\end{array}$ & $\begin{array}{c}\text { Cost of } \\
\text { measures } \\
\text { (million) }\end{array}$ \\
\hline $\begin{array}{c}\text { Decontamination } \\
\text { Evacuation }\end{array}$ & 101.4 & 10984.5 & 9898.4 & 48.6 & 36.6 \\
$\begin{array}{c}\text { Evacuation and } \\
\text { Decontamination } \\
\text { Permanent } \\
\text { Resettlement }\end{array}$ & 176.2 & 3779.3 & 3412.6 & 1270 & 1317.6 \\
\hline
\end{tabular}




\subsection{Establishment and solution of evaluation model}

In this paper, the nuclear emergency decision-making evaluation model is divided into three layers, as shown in figure 1. The highest layer is the target layer that is the optimal scheme, the second layer is the criterion layer that is the five evaluation indicators of the scheme, and the third layer is the program layer that is four alternative solutions.

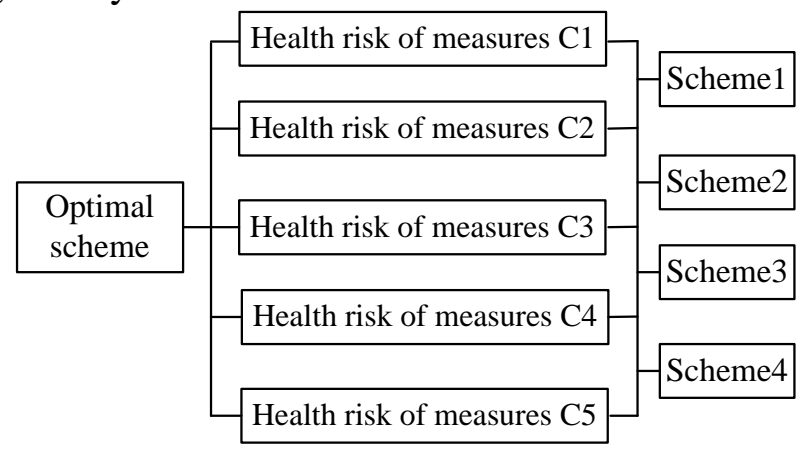

Fig.1 Hierarchy decision model of nuclear emergency

1) Determine the weight of each criterion in the target

Using the expert scoring method, the importance of the above 5 criteria sort is as follows: $C 1>C 2>C 3>C 4>C 5$. Experts believe that the first evaluation indicators and fifth indicators are significantly important, and the comparison scale b of basic point is equal to 7 . The calculation results are as follows:

$$
\text { Weight vector: } w=\left[\begin{array}{lllll}
0.47 & 0.27 & 0.14 & 0.08 & 0.04
\end{array}\right]
$$

2) Determine the weight of each scheme

The weight of each scheme for each criterion can be calculated as shown in table 2 .

Tab.2 Weighted vector of projects

\begin{tabular}{llllll}
\hline Attribute & $\begin{array}{l}\text { Health } \\
\text { risk of } \\
\text { measures }\end{array}$ & $\begin{array}{l}\text { Collective } \\
\text { dose to } \\
\text { prevent }\end{array}$ & $\begin{array}{l}\text { Maximum } \\
\text { dose to } \\
\text { preven 他 }\end{array}$ & $\begin{array}{l}\text { Direct } \\
\text { cost of } \\
\text { measure }\end{array}$ & $\begin{array}{l}\text { Cost of } \\
\text { measures }\end{array}$ \\
Scheme 1 & 0.27 & 0.14 & 0.14 & 0.61 & 0.61 \\
Scheme 2 & 0.14 & 0.08 & 0.08 & 0.10 & 0.04 \\
Scheme 3 & 0.51 & 0.27 & 0.27 & 0.25 & 0.25 \\
Scheme 4 & 0.08 & 0.51 & 0.51 & 0.04 & 0.10 \\
\hline
\end{tabular}

3) Calculate the comprehensive weight

According to formula (8), the comprehensive weight of each scheme is calculated as follows: 


$$
W=\left[\begin{array}{llll}
0.26 & 0.11 & 0.38 & 0.25
\end{array}\right]
$$

\section{Sensitivity analysis of model}

The variation rule of each scheme weight value with the parameter can be shown in figure 2 . According to the figure 2, the four scheme weight values have small changes along with the parameters, and the final scheme ranking of advantage and disadvantage is not changed, so it can be conclued that the model has better stability.

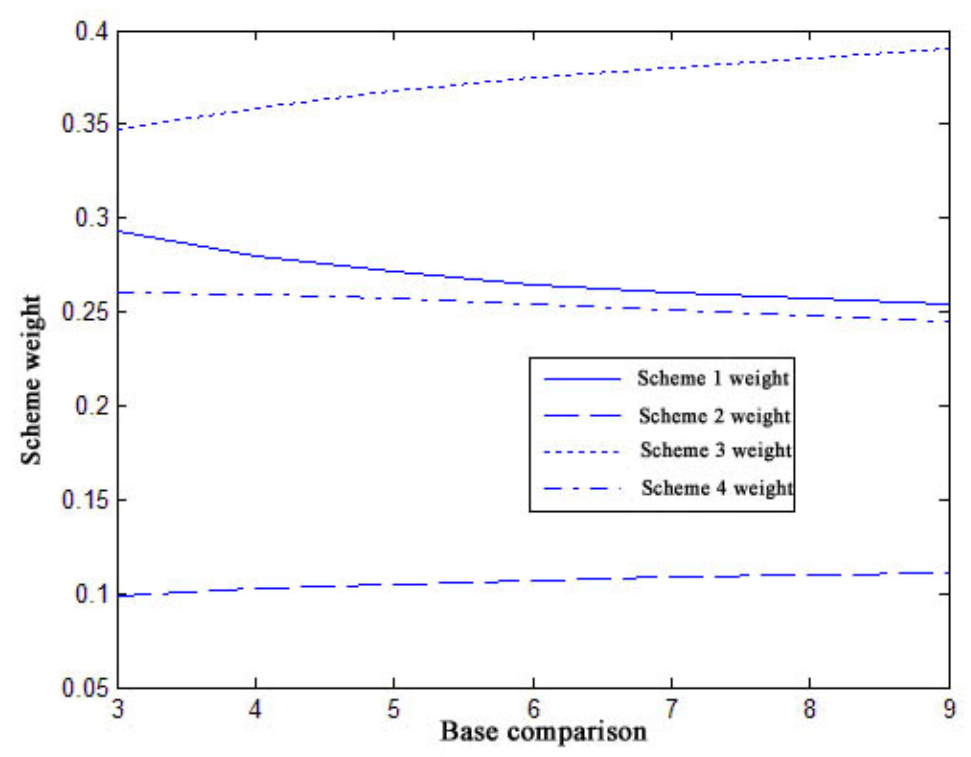

Fig.2 Sensitivity analysis of the model

\section{Conclusion}

Aiming at the deficiency of the traditional AHP method, the three scale AHP method is put forward in this paper and the evaluation model is established. Through the analysis of the examples, it can be conclued that the model has good stability and high resolution and the model is more easily to practice, so it can provide a new solution for the optimization analysis of nuclear emergency decision.

\section{References}

[1] Hengde Wang. Procedures and methods of radiation protection optimization[J]. radiation protection, 1995, 15 (2): 147-157.

[2]Nengzhi Lu, Yongxing Zhang, Xishou Cao, etc.The application of fuzzy decision theory in the nuclear accident emergency decision[J]. Nuclear science and engineering, 2002, 22 (2): 152-156.

[3] Dongqin Zheng, Chun Zhang, Xiao Zhang, etc. The application of nuclear power plant accident emergency fuzzy decision model [J]. nuclear power engineering, 2004, 25 (2): 168-171. 